\title{
Beyond the Legislation for Sickle Cell Disease Prevention - Getting the Right Outcomes
}

\author{
Ogbonna Collins Nwabuko, 2, 3, *, Ransome Eke ${ }^{4}$, Mwayabo Jean Claude Kazadi ${ }^{5}$ \\ ${ }^{1}$ Department of Hematology and Blood Transfusion, Federal Medical Centre, Umuahia, Abia State, Nigeria; \\ ${ }^{2}$ Department of Hematology, College of Health Science, Abia State University, Aba Campus, Abia State, Nigeria; \\ ${ }^{3}$ Department of Public Health Sciences, Walden University, Baltimore, USA \\ ${ }^{4}$ Department of Health Science, University of Alabama, Tuscaloosa, USA \\ ${ }^{5}$ Center for Disease Control Epidemic Control Project, Catholic Relief Services, Lusaka, Zambia
}

Email address:

ogbollins2002@yahoo.com (O. C. Nwabuko)

${ }^{*}$ Corresponding author

\section{To cite this article:}

Ogbonna Collins Nwabuko, Ransome Eke, Mwayabo Jean Claude Kazadi. Beyond the Legislation for Sickle Cell Disease Prevention Getting the Right Outcomes. American Journal of Internal Medicine. Vol. 7, No. 3, 2019, pp. 56-65. doi: 10.11648/j.ajim.20190703.12

Received: February 26, 2019; Accepted: April 23, 2019; Published: June 12, 2019

\begin{abstract}
This study aimed at highlighting benefits derivable from legislation for Sickle cell disease (SCD) prevention using the three levels of health legislative power (primary, secondary and tertiary). It was an evidence-based integrative review of 54 references related to SCD, epidemiology, management, and legislation for its control over the past three decades (1979-2018). Two keywords (SCD and Legislation/Policy) were used as search strategy to identify the problem, intervention, and outcome evaluation of the research questions. MeSH, Medline, CINAHL, PubMed, Cochrane Database Systematic Review, Google Scholar and African Journal Online were search databases reviewed. The expected outcomes were categorized into three levels of benefits. They were primary, secondary and tertiary categories of benefit. While the primary category would institutionalize pre-genetic counseling in the health institutions, the secondary and tertiary groups would establish screening (prenatal and newborn)/comprehensive care and curative interventions (i.e., investigational therapies and stem cell transplantation) respectively for people living with SCD. These interventions will enhance SCD surveillance, screening, auditing, health needs assessment, treatment, control, and prevention in the target audience. Conclusions The legislation for Sickle Cell Disease prevention in the target population would promote early disease detection, treatment, and prevention. We expect that with an increase in case ascertainment, the disability-adjusted life year (DALY) would reduce so also other complications. This legislation will diffuse new innovations in SCD management and research which will ultimately improve the health indices of people living with the disease globally.
\end{abstract}

Keywords: Sickle Cell Disease, Legislation, Prevention, Outcome, Surveillance

\section{Introduction}

SCD is a group of hemoglobin disorders in which abnormal beta-globin gene, known as sickle cell gene, is inherited either in a homozygous (SS) or heterozygous state (i.e., SC, SD, S $\beta$ ) [1]. It is one of the non-communicable diseases (NCDs) of public health importance globally [2].World Health Organization considers SCD the most prevalent genetic disease worldwide, especially in Africa [3]. In 2015, the regional office in Africa recommended the need for developing national SCD control programs using advocacy, counseling, early detection, surveillance, research, treatment, community education and partnership as intervention strategies [4]. Other studies have suggested the need for governmental policies and standards to address SCD that focus on health system strengthening [5-8]. This review focuses on a comprehensive strategy on SCD prevention at an organized all-inclusive pattern.

The PICO model of systematic literature review guided the process used for this review [9-10]. The model consists of four steps: a) problem identified, b) interventions identified, c) comparison of the target population with or 
without intervention, and d) the expected outcomes of interventions. The "problem identified" in this context is the sickle cell diseases burden", while the" interventions identified" include legislation at the primary, secondary and tertiary levels of SCD disease prevention. Also, an attempt was made to compare the outcomes of intervention in a population with some legislation on SCD prevention to that without any legislation. The inclusion criteria included fulltext reports, web pages, or articles (research-based or description of existing programs or policies), published between 1979 and 2018, and focused on the epidemiology of SCD such as incidence, prevalence, screening, treatment and policy guidelines in both the adult and pediatric populations. Databases introduced in the initial search included $\mathrm{MeSH}$, Medline, CINAHL, PubMed, Cochrane Database Systematic Review, Google Scholar, and African Journal Online using keywords: 'Sickle Cell Disease (SCD)", 'Sickle Cell Anaemia (SCA)", SCD/SCA Prevention, Control, Screening, Treatment and Legislations" cross-listed with keywords "Adult" and "Children". Additional information gathered through examination of the reference list of the reviewed papers. A total of 54 references met the inclusion criteria [1112].

Following the retrieval of the articles, their strengths and weaknesses assessment by co-authors and the major concepts identified. This paper presented a synthesis of the reviewed articles and expected outcomes of possible interventions on SCD prevention. A discussion of the implications of the findings on legislation, practice and future research highlighted. This article is analysed and grouped according to the following categories: epidemiology, health legislation, curbing the burden of SCD using health legislative power, challenges of SCD prevention legislation and recommendations [11].

\section{Epidemiology}

The estimated births affected with SCD annually worldwide is 300,000 , out of which $75 \%$ are said to be living in sub-Saharan Africa [13]. The global statistics of SCD shows that the African continent bears the highest burden of sickle cell disease with a prevalence of about 119 births per 1000 live births while the prevalence in the American continent (South America and USA) and some parts of middle east (Asian continent) is 0.1-0.99 births per 1000 live births (Figure 1) [14]. Sickle cell anemia (SCA) is the homozygous variant of SCD, and its clinical severity depends on the haplotypes that exist in the betaglobin chain. There are about five haplotypes which determine the severity of sickle cell anemia (Benin, Cameroun, Bantu, Arabian/India, and Senegal) [15]. The clinical severity of SCA relatively depends on the quantity of fetal hemoglobin linked to the haplotypes. The Bantu haplotype, for example, is more clinically severe compared to the Arabian and Senegal haplotypes (Figure 2).

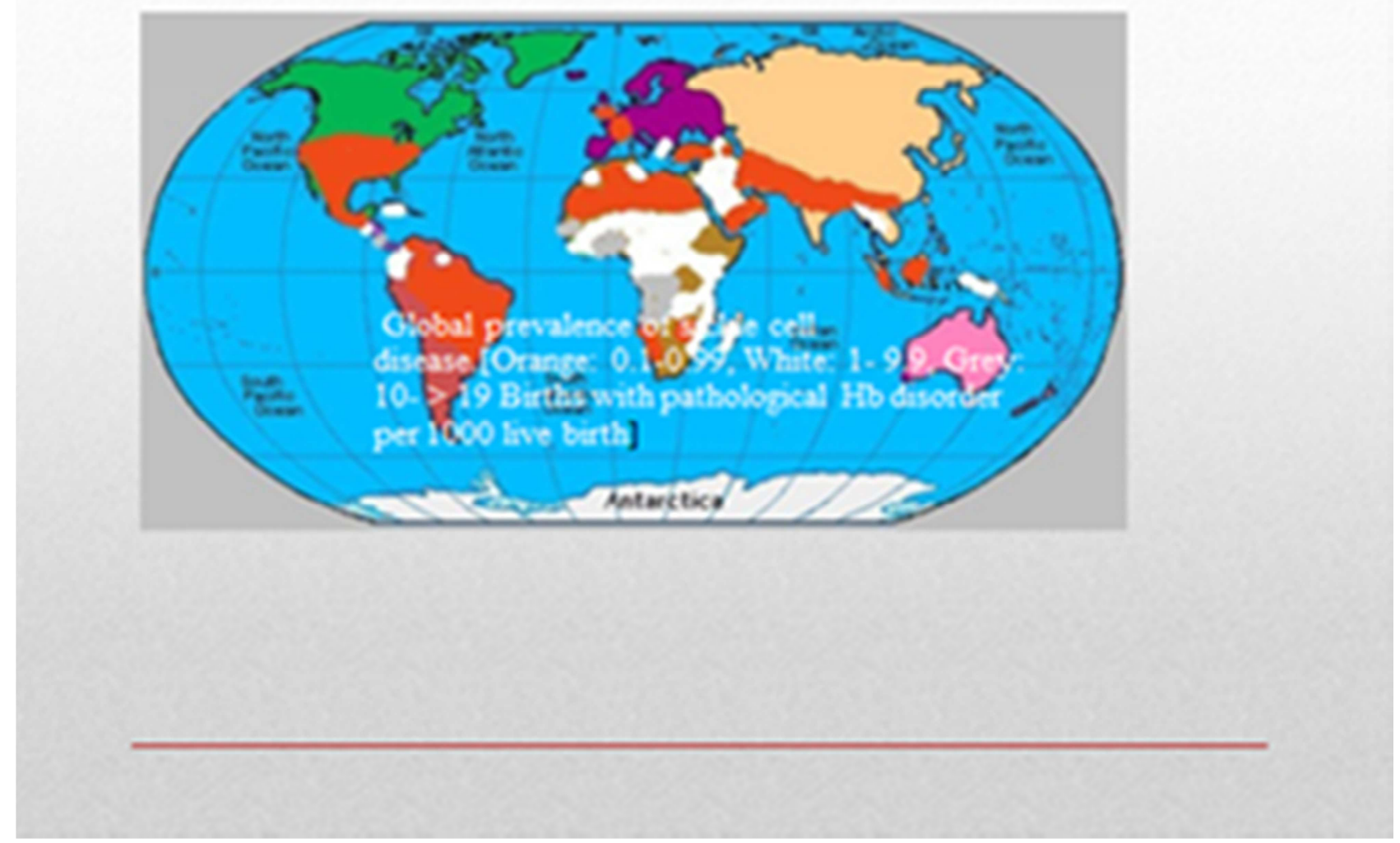

Figure 1. Global statistics of Sickle cell disease [Orange: 0.1-0.99; ] White: 1-9.9; Grey: 10->19 Births with pathological hemoglobin disorder per 1000 live births]. 


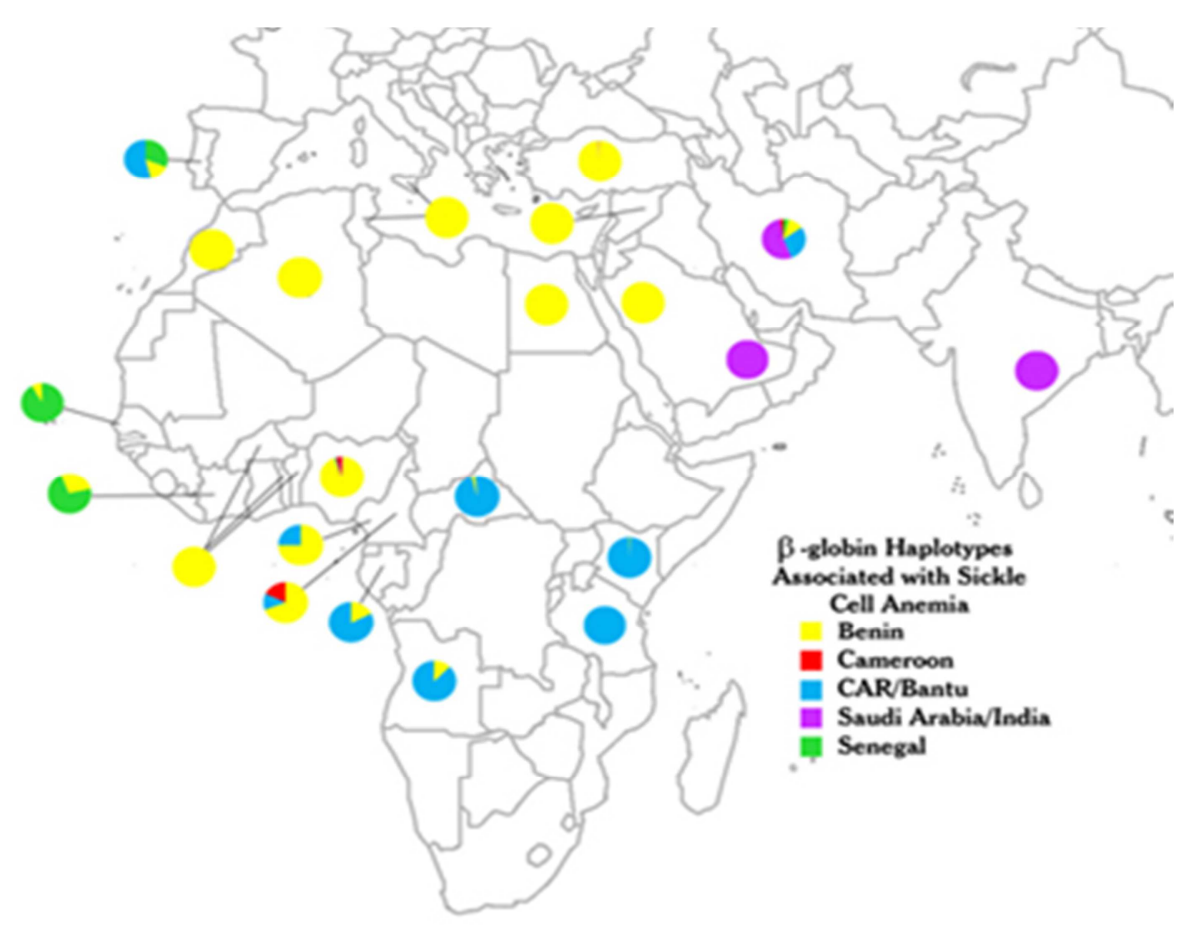

Figure 2. Global distribution of five different sickle cell anemia haplotypes [15]. Key: CAR = Central African Republic.

The global prevalence range of SCD is 20-25 million, out of which 6-9 million infants are born in Africa annually. An estimated $50-80 \%$ of children born with SCD in Africa die before the age of 5 years [16]. About one in every twelve (1:12) Africans has sickle cell trait while SCD occurs in one in every six hundred (1:600) AfricanAmerican infants. There is a racial disparity in the prevalence of this genetic disease with the highest prevalence in African, African-American, Mediterranean (Italian, Sicilian, Greek), Middle Eastern, East Indian, Caribbean, and Central or South American descent (Figure 1). There is no gender disparity in the disease occurrence (M: F ratio is 1:1). The affected patients are usually asymptomatic at first few months of birth, but begin to manifest clinical features of the disease at about 4-6 months of age. The average life expectancy of people living with SCD is about 42 years for men and 48 years for women [16-17].

Nigeria has the highest prevalence of SCD with about $90,000-150,000$ births/year which is $30 \%$ of the global prevalence of SCD and national prevalence of 1-3\% [3]. The implication is that about $1.98-5.94$ million people are living with SCD in Nigeria based on the recent national population statistics [14]. SCD ranks top ten NCDs in Nigeria with over forty million Nigerians carrying the abnormal sickle cell gene (SCT) [18]. The estimated prevalence rate in Abia State, a state in southeastern Nigeria is about $1.8 \%$ which is in keeping with the national prevalence range [19].

About 90,000 people are living with SCD in the USA, out of which $90 \%$ are African-Americans while the remaining ten percent are Latinos and Hispanics [20]. It is worthy of note that the annual cumulative incidence of
SCD in Nigeria is higher than the national prevalence of SCD in the USA. New York has the highest burden of sickle cell disease followed by Florida and Texas (Figure 3 ). The cost of managing SCD could be burdensome to any national economy [20]. SCD accounts for 113,000 hospitalizations annually with an annual expenditure of 488 million dollars (approximately $\$ 0.5$ billion) in the USA [20].

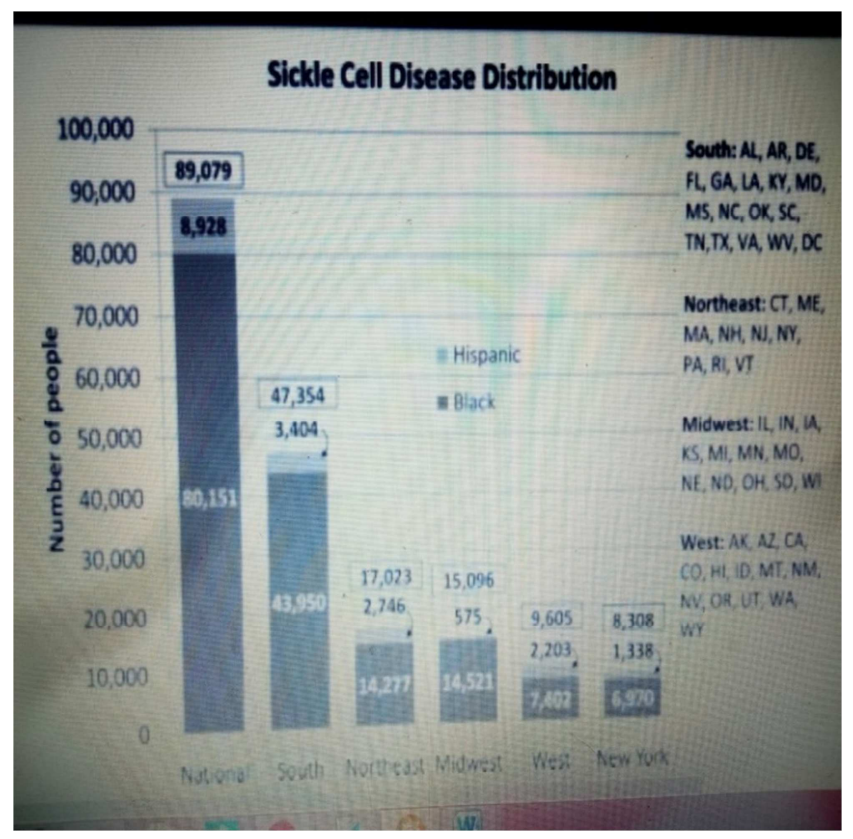

Figure 3. The National statistical data of SCD in the United States of America [20].

Sub-Saharan Africa made up of forty three member countries bears the highest burden of SCD in the African 
continent. The major sub-Saharan countries with high sickle cell disease burdens include Nigeria $(91,011$ births/year), Democratic Republic of Congo (39,743 births/year), Tanzania (11,877 births per year), Uganda (10,877 births per year), Angola (9,017 births per year), Cameroun (7,172 births per year), Zambia $(6,039$ births per year), Ghana $(5,815$ births per year), Guinea $(5,402$ births per year) and Niger (5,310 births per year) giving a total of 242,187 births per year [21].

A demographic picture of SCD in a hospital-based study has shown that more diagnoses of the disease made at the pediatric age group compared to the adult counterpart in Nigeria. In an unpublished work on the socio-demographic pattern of SCD patients seen in Abia state, southeastern Nigeria, the prevalence ratio of adult to pediatric age group was 1:2.2 while their peak months of diagnosis were September and October respectively. These further show that a reliable estimate of the population affected by SCD is necessary to guide the efficient and prudent allocation of public health resources [22].

\section{Health Legislation and SCD}

The government has a role to play in safeguarding the health of its citizen. Health, therefore, is not necessarily something medical or something you fix to the doctor or availability of technology, medicine or high gross national product. It is, rather, something that is rooted in our culture, social behaviors and how we allocate our resources and opportunities which will ultimately lead to improved quality of life [23].

Health policy is one of the major determinants of the population health in any nation. The social environment which is the place where people are born, grow, live, work and age is a reflection of the health policy of the government. It is one of the greatest influencers of health outcomes of any nation [24-25]. Health outcomes (otherwise known as health indices) in this context include the average life expectancy from birth of the population and the infant mortality rate (IMR). The IMR defined as the number of deaths of newborn per 1000 live births per year [26].

The United Nations and the World Health Organization use the health outcomes of the nation's population to rank the nation. For example, the average life expectancy of the African population as of 2015 was that of European union population as at the 1930 s (i.e., 88 years backward) (Figure 4a) [27]. Nigeria ranks 214th (i.e., with average life expectancy from birth of 53.8 years) out of 224 member countries of the United Nations based on the Central Intelligence Agency (CIA) World Factbook (2017) [28]. Also, Nigeria is the eighth worse country to be born on earth based on the high IMR of $69.8 / 1000$ live births per year (Figure 4b) [29]. This figure is not comparable to countries such as Canada which rank twenty-first among the United Nations member countries with average life expectancy from birth of 81.9 years and IMR of 4.5 per 1000 live births per year [28-29].

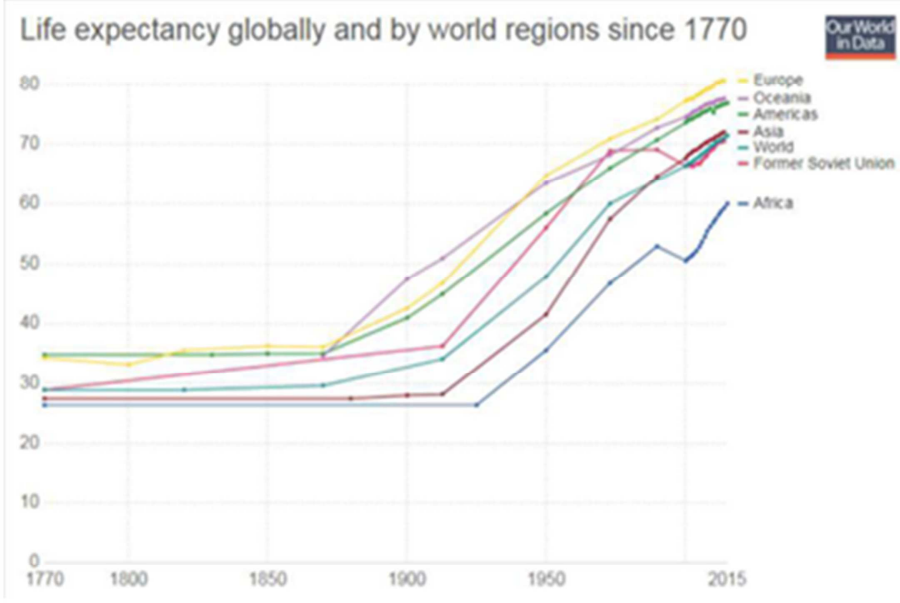

(a)

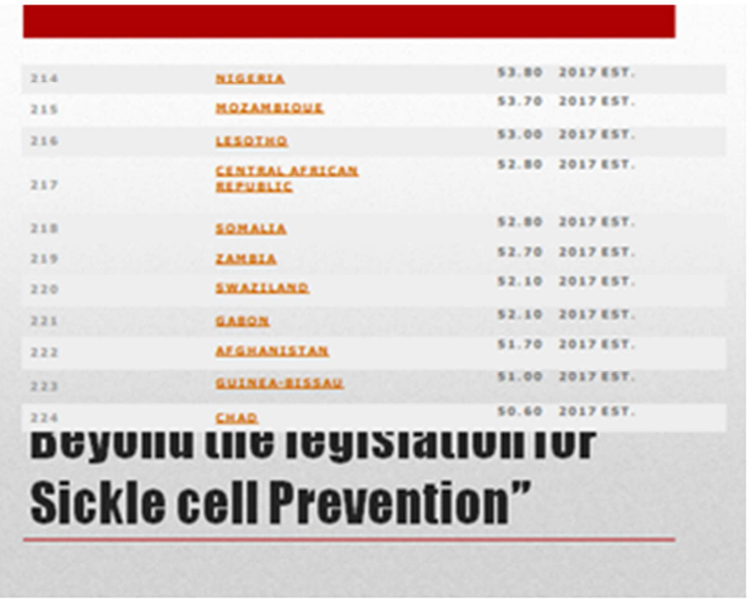

(b)

Figure 4. (a)Our World in Data showing life expectancy by world regions since 1770 [27] (b) World Fact book 2017 showing the ten sub-Saharan African countries with least average life expectancy [28].

Health promoting and protecting policies drive the healthiest nations in the world. Good roads, good hospitals, education, energy, social empowerment, reduced income gap, and a good economy are the products of health policies [23-24]. Unfortunately, the reverse is the case in most lowincome countries especially those of the sub-Saharan African countries ravaged by political anarchy, religious wars, and high-income gaps. There are rarely good policies in these nations as it is today. The few that are present are not implemented, living the nations under the category of countries with the worst health indices in the world [30].

The benefits of promulgating good health policies, more especially, that of SCD in a country with the highest burden of the disease globally cannot be over-emphasized. It is a holistic approach to achieving improved life expectancy and reduced mortality rates of the target population. The median 
survival interval of the Nigerian SCD patient is half of that of the United States of American counterpart (i.e., 21 years versus 42 years) [31-32]. The identified causes of the short lifespan of people living with SCD in the region are preventable if the right health policies are in place.

The poor health indices in the weak nations are attributable to lack of health-promoting policies from the government. Most sub-Saharan African countries, for example, have poor health policies. It is not necessarily due to a lack of financial strength to drive health services; instead, it is a lack of political commitment of the government. In Nigeria, for instance, the annual budget on health is about $5 \%$ of gross domestic product (GDP) which is grossly below the $15 \%$ Abuja declaration target in 2012 [30]. It has hindered achieving the Millennium Development Goals (MDGs), especially goals numbers one, 4, 5 and six that have to do with the eradication of extreme poverty and hunger, reduction of child mortality, improved maternal health and combating HIV/AIDS, malaria, tuberculosis and other diseases respectively [30]. When you compare Nigeria to Canada, you will find that Canada is far better than Nigeria in health outcomes, because the Canadian government embraces an upstream approach in dealing with health problems, a term popularly known as socialized medicine or preventive health. It is somewhat synonymous with other healthy countries such as Monaco, Japan, and Luxembourg. Most healthy nations use an upstream approach to address the population health problems. They can achieve this by promoting protective and disease preventive health policies [33]. On the other hand, most developing nations with weak health indices use a downstream approach in dealing with their health problems. In the downstream path, preventive and socialized medicine are minimal, while Medicaid and curative approach are strategies in dealing with health problems. While the former is a cheaper and proactive approach, the latter is reactive and capital intensive [34]. The United States of America spends over two trillion dollars annually on Medicaid (i.e., greater than half of the world annual expenditure on Medicaid). Despite this huge amount, the United States is not the healthiest country in the world [35].

Health promoting policies invest in human resources, education and favorable determinants of health such as proper housing, social amenities, clean environment, potable water, economic empowerment and health care of the people. They tend to favour actualization of the eight Millennium Development Goals (MDGs) namely eradication of extreme poverty and hunger (MDG-1), universal primary education (MDG-2), promotion of gender equality (MDG-3), reduction of Child mortality (MDG-4), improved maternal life (MDG5), combating HIV/AIDS, Malaria, Tuberculosis and other disease trajectories (MDG-6), environmental sustainability (MDG-7), and global partnership for development (MDG-8) [30]. The health-promoting policies favor reduced incomegap and tend to create an egalitarian society where there are caring and sharing. These are the indices of a healthy nation, which invariably justify the high average life expectancy and low IMRs of high-income countries compared to low-income countries [36]. They work in synergy to develop the nation, prevent diseases and protect the social environment.

Health policy is enacted by government through sponsorship of a health bill that has to do with particular health condition. It is a litmus test of the health impact of any government on the governed populace. A good government owes it as a priority to enact laws that will promote conditions of public health importance.

SCD is one of the diseases of public health importance that requires political, legislative and cultural attention. Legislation on SCD prevention will pave the way for proper auditing, surveillance of SCD and the blood types of the population for precise mapping, budgeting and prudent allocation of resources. With this legislation, the SCD registry or database is established in all levels of health institutions, especially in primary health centers found in suburban areas. It will give rise to proper documentation which may ultimately lead to the establishment of local and national Surveillance Epidemiological End-Result (SEER) statistics for SCD. With this establishment, proper case ascertainment, epidemiology, incidence rate, prevalence, birth rate, mortality rates, and the $\mathrm{ABO}$ Rhesus blood types of people living with SCD will be documented appropriately. This legislation could be life-saving as it promises to reduce the protocols of blood grouping required for emergency medical interventions, especially in cases of severe anemia due to road traffic accidents, medical and surgical conditions that need an urgent blood transfusion.

\section{Prevention of SCD Using the Three Levels of Health Legislative Power}

There are three practical steps of reducing the burden of SCD to the barest minimum locally and globally. These steps also regarded as the benefits (positive outcomes) of the legislation for sickle cell disease prevention. They include:

Primary Preventive step (Genetic counseling \& Screening)

Secondary Preventive step (Therapeutic Intervention)

Tertiary Preventive step (Curative Intervention)

The primary preventive step, otherwise known as the genetic counseling and screening strategy, is the upstream approach of prevention of SCD. It is the method usually embraced by the wealthier nations, and it is cost effective. On the other hand, the second and third preventive strategies are the downstream approach of SCD prevention. "Prevention" in this context may connote halting the occurrence of the abnormal sickle gene (genetic counseling); minimizing the complications caused by SCD (early detection by screening and comprehensive care), and reversal of the abnormal gene to normal gene using current scientific innovations (curative or tertiary intervention). The primary purpose of the secondary and tertiary levels of preventive intervention is to improve the quality of life of already established SCD patients. While the first step is the cheapest approach of preventing the disease, the 2nd and third steps 
are capital intensive [37].

\subsection{The Primary Preventive Step}

The following interventions fall under primary preventive step: pre-marital genetic counseling (mainly for school-aged and couples who are about to marry), prenatal screening (2nd and 3rd Trimester) and newborn screening (within 72 hours of birth). "Genetic Counseling" in this context, connotes discouraging sickle cell trait partners (carrier or AS) from marrying each other. This process could be initiated as early in life as possible by conducting a screening test. Several studies have recommended the need for genetic testing and newborn screening for SCD [6-8]. Genetic counseling may start from the school-age period and in couples intending marriage, a term is popularly known as pre-marital genetic counseling. Newborn screening and prophylactic intervention (NSPI) has been found to reduce early mortality and improve the life expectancy of people living with SCD. It is achievable by increasing the incidence rate of SCD (case ascertainment) and reduction of Disability Adjusted Life Year (DALY) outcome [38]. The preventive interventions include insecticide-treated mosquito net, Folic acid supplementation, prophylactic antimalarial, penicillin therapy and immunization against bacterial infections. It is a cost-effective upstream approach used by most high-income countries [37-38]. This strategy has the potential of reducing the burden of SCD in sub-Saharan Africa especially if the method of screening is simplified (i.e., Point of Care Testing, POCT) and expanded to the rural areas [39]. Prenatal diagnosis detects the sickle cell gene while in-utero. The old invasive traditional methods such as Chorionic villus sampling (CVS amniocentesis, and cordocentesis) are currently replaced by non-invasive prenatal diagnosis (NIPD) with the revelation of cell-free fetal DNA (cffDNA) in maternal plasma and serum. This technique has the potential of identifying the fetal sex, fetal Rhesus D and paternal alleles in maternal plasma of SCD using highresolution melting (HRM) analysis [40].

\subsection{The Secondary Prevention \\ (Comprehensive/Therapeutic Intervention)}

This step involves the establishment of a comprehensive health care system for screening and palliative care of people living with SCD. The health system must have the following requirements:

\subsubsection{Diagnostic Facilities}

These include facilities for conducting baseline investigations, diagnosis, monitoring, and prognostication of SCD progression. The only way the citizens can know their genotypes and blood group types is to access adequate diagnostic facilities. When the diagnosis is established, disease progression must be monitored to prevent a crisis. Three parameters to look out for during follow-up care include the quantity of non-glycated hemoglobin (A0), Sickle cell gene (S-window), and fetal hemoglobin (HbF the Childhood marker for adult life expectancy) [41].

\subsubsection{Institutionalization of Palliative Care Policy for SCD}

SCD is a life-threatening illness, and therefore, requires a holistic approach in the care of people living with SCD. It is the care that assures improved quality of life (QOL) and life expectancy of the SCD patients [42].

\subsubsection{Regular and Novel Regimens/Investigational Drugs}

The conventional drugs are necessarily the preventive interventions discussed earlier, in addition to supplemental oxygen, rehydration, and analgesics, depending on clinical state or crisis at presentation. The novel/investigational regimens include hydroxyurea therapy (HUT), Voxelotor (GBT-440), Lenti Globin (LG BB305), L-glucosamine (Endarin) $^{\mathrm{R}}$ and other anti-oxidants undergoing clinical trials. The HUT acts by increasing $\mathrm{HbF}$, hence, reducing the episodes of SCD crisis and the need for repeated blood transfusion (especially in transfusion-dependent SCD or R/R SCD) [16]. Most centers of excellence for managing SCD have HUT policy, especially in the developed country. However, its use in Africa is low due to uncertainty about the risk and benefits [11]. Voxelotor (GBT-440) was created by Global Blood Therapeutics from HOPE (Hemoglobin Oxygen Affinity Modulation to inhibit HbS PolymErization) study. It improves blood oxygen saturation and reduces hospitalization-induced vaso-occlusive crisis [43]. LG BB305 (Lenti Globin) is a therapeutic regimen which acts as gene therapy. It has a curative benefit [44]. More recently, a new investigational biologic therapy known as crizanlizumab, is about to be approved by the USA Food Drug Administration. This drug manufactured by Novartis will be useful in the prevention of SCD vaso-occlusive crisis.

\subsubsection{Safe Blood Transfusion Policy}

SCD patients in crises especially aplastic crisis will need a blood transfusion, and this must be accessible in a comprehensive health center dedicated for SCD. Voluntary Non-Remunerated Blood Donation (VNRBD) is highly recommendable. The current advocacy to set up a standard Blood bank centers dedicated for unpaid blood donation to handle emergency conditions should be promoted [45].

\subsubsection{Healthy Living (Nutrition/Food Supplement)}

Folic acid supplementation, L- Glutamine, Glutathione oxidase inhibitor, Thiocyanate-containing foods, Vitamin Bcontaining diet, seaweeds, and other food supplements are recommended as they are rich in anti-oxidants [46].

\subsection{Tertiary Prevention (Curative Intervention)}

The reversal of abnormal $\mathrm{Hb} \mathrm{S}$ to normal $\mathrm{Hb} \mathrm{A}$ and improved quality of life of people living with SCD are the tertiary preventive approach of the legislation. This policy and legislation will create research opportunities in SCD. Current Researches on SCD are predominantly targeted on complete remission (CR) or eradication of the S-gene in the patients. Such translational research works include: 


\subsubsection{Stem Cell Transplantation (SCT)}

Allogeneic stem cell transplantation (Matched Related Donor/Matched Unrelated Donor) is a promising curative therapy for SCD. High Survival rate and Disease-Free Survival intervals have been recorded in over one hundred and fifty children using HLA-identical siblings. In Nigeria SCT was carried out successfully on thirty one children, out of which, over twenty eight achieved CR [47].

\subsubsection{Sickle Cell Genomics Network of Africa}

The SickleGenAfrica is established to build local capacity among African scientists to enable them to study the genomics of the disease in the African continent. This initiative is playing a significant role in the human heredity and health of African continent (H3Africa). There are four study centers in Africa namely Nigeria, Ghana, Cameroun, and Tanzania [48].

\subsubsection{Gene Therapy}

A typical example is the LG BB 305. This could be a potent therapeutic ex-vivo gene transfer in severe SCD. A13-year old has achieved CR of clinical signs of SCD fifteen month after commencement of this regimen in France [44].

\section{Challenges of SCD Legislation and Recommendations}

\subsection{Implementation of Legislation}

Prevention of SCD is not going to be an easy task because you cannot completely eradicate sickle cell gene from over $5 \%$ of the global population living with hemoglobin disorder (hemoglobin S and thalassemia) [39]. The SCT (carrier state), which constitutes about forty million Nigerian populace, confers immunity to carriers living in a malariaendemic region. Therefore, eradication of the S-gene from these carriers will predispose them to more malaria attacks, hence, increasing the burden of malaria in the area. Apart from that, there are other confounding genes which can combine with S-gene (i.e., you need only one S-gene and any other gene other than A-gene to have SCD) to give rise to $\mathrm{SCD}$. The heterozygous variant (Hb-SC) is more common than the homozygous Hb-SS variant in other West African countries outside Nigeria [48]. We recommend that these confounding genes be investigated on as well.

\subsection{Funding}

One of the challenges facing SCD globally is underfunding [49]. Management of SCD is capital intensive. The investigations, treatments and research projects require funding [20,37]. It could be a more difficult task for subSaharan African nations where annual budgets on public health expenditures are less than the stipulated fifteen percent in Abuja declaration [30]. Also, some disparities come into play in the private and public funding of SCD because of the perception that it is a disease of the black. Funding is required to embark on mass genotyping and blood grouping serology for populations that run in millions. There is a need for both local and international collaborations to achieve this goal [49-50].

\subsection{Newborn Screening}

This is where most developed countries are now in SCD management. However, only very few newborns screen for SCD within 72 hours of birth in sub-Saharan Africa [38]. The reasons could be multifactorial. It may be due to a lack of government commitment or due to lack of proper planning process and implementation from the coordinating centers [51]. Can it be possible to know the genotype of every newborn in any given population within 72 hours of birth? Yes, it can be possible, if and only if highly subsidized costeffective innovations are adopted. The SickleScanR POCT is a prototype of this novel innovation for newborn screening. Another possibility of this actualization is when there is an equal distribution of resources for screening in all the geopolitical zones. A comprehensive national database of the crude birth rate will be an essential epidemiological tool for this process to be successful. The crude birth rate measures the rate at which people are born in a community.

\subsection{Public Health Awareness Campaign on SCD}

The awareness campaign should target urban and rural communities. The vehicle of information dissemination should include mass media (radio, TV adverts), social media (i.e., Facebook, Whatsapp, Blog, Flicker, Twitter and Instagram, etcetera), posters and bills. The campaign language must be culturally friendly, relevant and understandable to mitigate the challenges of health literacy and culture barriers. There is a need to continually engage the community using Community-Based Participatory Research (CBPR) members [52-53].

\subsection{Establishment of Database System}

Although the legislation will improve research, surveillance, and treatment of sickle cell disease, a bill to this effect was passed by the senate and house of representative of the United States of America in 2018 (115th congress). It is the only way storage of information generated from fieldwork can be guaranteed [54]. There is a need to engage public health experts especially the Epidemiologists and Biostatisticians to craft an SCD surveillance department under the federal ministry of health. One of their roles should be mapping SCD in all the geopolitical zones of the country.

\subsection{Increase in the Burden of Malaria}

The burden of malaria in malaria-endemic regions of subSaharan Africa is a big toll on the SCD burden. It is because of the link between sickle cell hemoglobin and malaria resistance, especially in SCT carriers [55]. The higher the burden of malaria, the more likelihood of SCD crisis $[21,56]$. Reduction in the malaria burden will go a long way to reduce SCD burden via improved quality of life, increase life expectancy and reduced 
mortality rate. On this note, good hygiene, environmental sanitation, and prophylactic interventions have a place in the SCD trajectory and prognosis.

\subsection{SCD and Other Hemoglobinopathies Screening Tests}

Hemoglobinopathy screening is strongly recommended in policy guidelines of all health institutions. However, the challenge will be on the implementation. This is where H3Africa and Sickle cell genomic network of Africa should make their impact in the health institutions $[19,48]$.

\section{Conclusion}

The legislation for SCD prevention will promote early detection, treatment, and prevention. When the case ascertainment of the disease increases, the disability-adjusted life year (DALY) related complications will reduce.

There is a need to stratify this legislation into primary, secondary and tertiary policies in other to holistically address SCD prevention or control. It will pave the way for further research and strengthening of the health system. It will also diffuse innovations on SCD management which will ultimately improve the health indices of people living with the disease globally.

Successful execution of this legislation will depend on adequate public health awareness campaign; proper planning and engagement of the target group; adequate funding to provide resources and supports; implementation of the identified interventions and periodic evaluation of the effectiveness of the outcomes. A political commitment and global partnership are needed to achieve these goals.

\section{References}

[1] Cooper R. A note on the biologic concept of race and its application in epidemiologic research. Am Heart J 1984; 108 (3 Pt 2): 715-22.

[2] United Nations General Assembly. Recognition of sickle-cell anemia as a public health problem. United General Assembly; 2009.

[3] World Health Organization. Management of birth defects and hemoglobin disorders. Report of a joint WHO-March of Dimes meeting. World Health Organization; Geneva, Switzerland; 2006.

[4] World Health Organization Regional Office for Africa. Sickle cell disease prevention and control; 2015. Available at: http: //www.afro.who.int/en/clusters-a-programmes/dpc/noncommunicable-diseases-management-ndm/programmecomponents/sickle-cell-disease.html.

[5] Bosu WK. A comprehensive review of the policy and programmatic response to the chronic non-communicable disease in Ghana. Ghana Medical Journal 2012; 46 (Suppl.2): 69-78.

[6] Modell B, Darlison M. Global epidemiology of hemoglobin disorders and derived service indicators. Bulletin of the World Health Organization 2008; 86 (6): 480-487.
[7] Ohene-Frempong K, Oduro J, Tetteh H, Nkrumah FK. Screening newborns for sickle cell disease in Ghana. Paediatrics 2005; 121 (S120). Available at: http: //dx.doi.org/10.1542/peds.2007-22022UU.

[8] Tshilolo L, Kafando E, Sawandogo M, Cotton F, Vertongen F, Ferster A, et al. Neonatal screening and clinical care programmes for sickle cell disorders in sub- Saharan Africa: Lessons from pilot studies. Public Health 2008; 122 (9): 933941.

[9] PICO Model. Available at: http: //researchguides.uic.edu/c.php?g=252338\&p=3954402.

[10] Whittemore R and Knafi K. The integrative review: Updated methodology. Journal of Advanced Nursing 2005; 52 (5): 546-553. Available at: http: //dx.doi.org/10.1111/j.13652648.2005.03621.x.

[11] Mulumba LL, Wilson L. Sickle cell disease among children in Africa: An integrative review and global recommendations. International J Afr Nursing Sciences 2015; 3: 56-64.

[12] Nwabuko OC, Nwamoh UN, Chikezie JA. A Retrospective Review of Ebola Outbreak in West Africa: Social Determinants and Control Measures. Epidemiology: Open Access 2018; 8: 360. doi: 10.4172/2161-1165.1000360.

[13] Center for Disease Control and Prevention - Global health reports, Nigeria. 2012. Available at https: //www.cdc.gov > nigeria $>$ wha $t>$ scd.

[14] Piel FB, Hay SI, Gupta S, Weatherall DJ, Williams TN. Global burden of sickle cell anemia in children under five, 2010-2050: Modelling based on demographics, excess mortality, and interventions. PLoS Med 2013; 10: e1001484.

[15] Gabriel A and Przybylski J. Sickle-cell anemia: A Look at Global Haplotype Distribution. Nature Education 2010; 3 (3): 2 .

[16] Aygun B and Odame I. A global perspective on the sickle-cell disease. Pediatric Blood \& Cancer 2012; 59 (2): 386-390. DOI: $10.1002 / p b c .24175$.

[17] Piel FB1, Patil AP, Howes RE, Nyangiri OA, Gething PW, Williams TN, Weatherall DJ, Hay SI. Global distribution of the sickle cell gene and geographical confirmation of the malaria hypothesis. Nat Commun. 2010; 1: 104. DOI.10.1038/ncomms1104.

[18] Akinyanju OO. A profile of sickle cell disease in Nigeria Annals of the New York Academy of science 1989; 565: 126136.

[19] Nwabuko OC and Okoh DA. Hemoglobinopathy- the old and new eras in a south-eastern Nigeria tertiary health center. Blood 2015126 (23): 4577. Available at: http: //www.bloodjournal.org/content/126/23/4577

[20] Brousseau DC, Panepinto, JA, Nimmer, M and Hoffmann, RG. The number of people with the sickle-cell disease in the United States: national and state estimates. Published online 21 October 2009 in Wiley InterScience (www.interscience.wiley.com). doi: 10.1002/ajh.21570

[21] Makani J, Cox SE, Soka D, Komba AN, Oruo J, Mwamtemi $\mathrm{H}$, et al. Mortality in sickle cell anemia in Africa: A prospective cohort study in Tanzania. PLoS ONE 2011; 6 (2): e14699. 
[22] Nwabuko OC, Alozie E, Chikezie K, Chukwuonye II, Ejele OA. Socio-demographic overview of sickle cell disease seen in Abia State: a single institution experience over seven years. National Society of Haematology and Blood Transfusion NSHBT 2018 Abstract 025.

[23] World Health Organization Commission on the Social Determinants of Health. Closing the gap in a generation: Health equity through action on the social determinants of health. Executive summary. World Health Organization; 2008. Available at http://www.who.int/social_determinants/final_report/csdh_fin alreport_2008.pdf.

[24] Bezruchka S. From womb to tomb: The influence of early childhood on adult health [Audio podcast] 2005. Available at http://www.alternativeradio.org/products/bezs002.

[25] Hunter D. Leading for Health and Wellbeing: the need for a new paradigm. Journal of Public Health 2009; 31 (2): 202204.

[26] Central Intelligence Agency. (n.d.). The world factbook. Available at https://www.cia.gov/library/publications/theworld-factbook/index.html.

[27] Max R. Life expectancy. Published online at OurWorldInData. Available at: https: //ourworldindata.org/life-expectancy.

[28] Country Comparison: Life Expectancy at Birth. Available at: https: //www.cia.gov/library/publications/theworldfactbook/rankorder/2102rank.html.

[29] Country Comparison: Infant Mortality Rate, Available at:

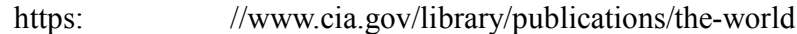
factbook/rankorder/2091rank.html.

[30] World Health Organization. Health systems in sub-Saharan Africa: What is their status and role in meeting the health millennium development goals? World Health Organization; 2012. Available at: http: //www.aho.afro.who.int/en/ahm/issue/14/reports/healthsystems-sub-saharan-africa-what-their-status-and-rolemeeting-health.

[31] Ogun GO, Ebili H, Kotila TR. Autopsy findings and pattern of mortality in Nigeria sickle cell disease patients. The Pan African medical journal 2014, 18: 30. Doi: 10.11604/pamj.2014.18.30.4043.

[32] Lanzkron S, Carroll P, Haywood C. Mortality rates and age at death from sickle cell disease: U. S., 1979-2005. Public Health Rep 2013; 128 (2): 110-116. doi: $10.1177 / 003335491312800206$.

[33] Public Health Agency of Canada; 2014. Available at http://www.phacaspc.gc.ca/index-eng.php.

[34] The Upstream Doctors; 2017. Available at: http://blog.ted.com/investigatigating-the-global-health-crisispaul-farmer-on-the-upstream-doctors/.

[35] Herbes-Sommers C, Smith LM. Health in America [Video excerpt]. In L. Adelman, Unnatural causes: Episode 1 - In sickness and wealth. United States: Public Broadcasting Service. 2008. Available at: http: //www.unnaturalcauses.org/video_clips_detail.php?res_id=21 3.

[36] World Health Organization. Health Promotion. World Health
Organization; 2018 [online] Available at: http: //www.who.int/topics/health_promotion/en/ [Accessed 24 May 2018].

[37] Nietert PJ, Silverstein MD, and Abboud MR. Sickle Cell Anaemia. Pharmacoeconomics 2002; 20 (6): 357-66. DOI. 10.2165/00019053-200220060-00001.

[38] Kuznik A, Habib AG, Munube D, Lamorde M. New-born screening and prophylactic interventions for sickle cell disease in 47 countries in sub-Saharan Africa: a cost-effective analysis. BMC Health Services Research 2016; 16: 304. DOI 10.1186/s12913-016-1572-6.

[39] Kanter J. Point-of-Care Testing in Sickle Cell Disease. In: Inusa BPD (eds). Sickle Cell Disease - Pain and Common Chronic Complications, 2016. Available at https: //doi/10.5772/64862.

[40] Yenilmez ED and Tuli A. New Perspectives in Prenatal Diagnosis of Sickle Cell Anemia. In: Inusa BPD (eds). Sickle Cell Disease - Pain and Common Chronic Complications, 2016. Available at https: //doi/10.5572/64646.

[41] Mpalampa L, Ndugwa CM, Ddungu H, and Idro R. (2012). Fetal hemoglobin and disease severity in sickle cell anemia patients in Kampala, Uganda. BMC blood disorders 2012; 12: 11. doi: 10.1186/1471-2326-12-11.

[42] Sepulveda C, Marlin A, Yoshida T, Ulrich A. Palliative care: the World Health Organization's global perspective. J Pain Symptoms Manage 2002; 24: 91-96.

[43] Estepp JH. Voxelotor (GBT440), a first-in-class hemoglobin oxygen-affinity modulator, has promising and reassuring preclinical and clinical data. American Journal of Hematology 2018; 93: 3. Available at https: //doi.org/10.1002/ajh.25042.

[44] Ribeil J, Hacein-Bey-Abina S, Payen E, et al. Update from Hgb-205 Phase $1 / 2$ Clinical Study of Lentiglobin Gene Therapy: Sustained Clinical Benefit in severe Hemoglobinopathies. Blood 2018; 128 (22): 2311. Available at http: //www.bloodjournal.org/content/128/22/2311.

[45] Nwabuko OC, Nnoli MA, Okoh DA, Chukwuonye II. Taming the tide of HIV and TTI Scourge in sub-Saharan Africa using autologous blood transfusion. Hematology and Leukemia Herbert Open Access Journals 2013; 1 (7). Available at https://doi.org/10.7243/2052-434x-1-7.

[46] Endari (L-glutamine) for Sickle cell disease. Available at https://sicklecellanemianews.com/endari-l-glutamine/.

[47] Isgro A, Paciaroni K, Gaziev J, et al. Haemopoietic stem cell transplantation in Nigerian sickle cell anemia children patients. Niger Med J. 2015; 56 (3): 175-179.

[48] Makani J, Ofori-Aquah S, Nnodu OE, Treadwell M, Royal C, and Ohene-Frempong K. Sickle cell disease and H3Africa: enhancing genomic research on cardiovascular disease in African patients. Cardiovascular J Afr. 2015; 26 (2H3Africa Suppl): S50-S55.

[49] Nwabuko OC, Okoh DA, Iyalla C, Omunakwe H. Prevalence of sickle cell disease among pregnant women in a tertiary health center in south-south Nigeria. Sub-Saharan Afr J Med 2016; 3: 132-6. DOI: 10.4103/2384-5147.190843.

[50] How Race Plays an Ugly Role in the Drastic Underfunding of Sickle Cell Research and Advocacy. Available at: http: //www.dailykos.com/story/2015/05/05/1382655/-How-race-plays 
[51] Green L, Kreuter M. Health program planning: An educational and ecological approach. 4th ed. New York: McGraw-Hill; 2005.

[52] Parker J C, Thorson E editors. Health communication in the news media landscape. New York, NY: Springer Publishing Company; 2009.

[53] Nwabuko OC, Igbigbi E, Ejele OA. Promoting Public Health Campaign on Awareness and Screening for Multiple myeloma in Nigeria. Archives of Hematology and Blood Diseases 2018; 1 (2): 15-20.

[54] Text-S. 2465-115th Congress (2017-2018): Sickle Cell Disease and Other Heritable Blood Disorders Research, Surveillance, Prevention, and Treatment Act of
2018/Congress.gov. Available at https://www.congress.gov > senate-bill.

[55] Fleming AF, Storey J, Molineaux L, Iroko EA, Attai ED. Abnormal hemoglobins in the Sudan Savanna of Nigeria. I. Prevalence of hemoglobins and relationships between sickle cell trait, malaria, and survival. Ann Trop Med Parasitol 1979; 73: $161-72$.

[56] Komba AN, Makani J, Sadarangani M, Ajala-Agbo T, Berkley JA, Newton CR, et al. Malaria as a cause of morbidity and mortality in children with homozygous sickle cell disease on the coast of Kenya. Clinical Infectious Disease, 2009; 49 (2): 216-222. DOI: 10.1086/599834. 